\title{
Female Labour Force Participation in India: Understanding the Nature and Constraints
}

Divya Gupta

PhD Scholar, Delhi School of Economics, Delhi - 110007, India; divyagupta@econdse.org

\begin{abstract}
Rising education of women and falling fertility has not translated into greater participation of women in the labour force. Understanding the nature of and factors affecting women's employment is pivotal to direct policy initiatives in addressing the issue. Using a nationally representative dataset, this study analyses various factors affecting women's employment with specific focus on the presence of young children in the household. The paper also studies the nature of employment as a 'work away from home' and 'full-year or not' and effect of various factors on the same. The study finds that apart from other factors, presence of very young children in the household acts a major constraint to a woman's participation in the labour market, ie., decreasing their likelihood to work. Moreover, even if a woman participates, presence of young children may affect the nature of work that she engages in. Whereas we find no effect of child-care responsibilities on the place of work of women, there is significant negative effect on women's nature of work being full-year if there are young kids in the household.
\end{abstract}

Keywords: Child-Care, Child-Care Institutions, Employment, Female Labour Force Participation, Patriarchal Norms JEL classification: J13, J16, J21, C01, C31, C35

\section{Introduction}

Flood of literature highlights a rather dismal and contradictory picture of India's growth story. While there are increasing incomes, participation of women in these income-generation activities is falling. Even with rising education and falling fertility, women in India do not correspondingly participate more in the labour force; in fact, they participate even lesser. The International Labour Organisation has ranked India's Female Labour Force Participation (FLFP) rate at 121 out of 131 countries in 2013, which is one of the lowest in the world. A more recent World Bank report on 're-assessing the drop in FLFP in India, April 2017 also demonstrates a similar picture. According to the report, around 19 million women and girls are no longer actively participating in the labour force, with the drop being more significant in rural areas (around 53 percent of the drop) than in urban areas.

This is particularly true of those women who have very young children, that is children in the age-group of $0-5^{\mathrm{a}}$. This can be explained by the 'primary caregiver' role of women (specifically, mothers) which is well acknowledged and documented in literature. Thus, among various constraints, one of the major constraints to a woman's decision to participate in the labour market can be the sole responsibility of taking care of very young kids, in the absence of any institutional support (like a well-functioning child-care system).

Given the background, this study thus aims to analyse the patterns of employment of women in India, discuss various factors affecting women's labour force participation and more specifically, discuss the impact of child-care responsibilities, which is proxied by presence of young children in the household, on women's work decisions.

Rest of the paper is organised as follows. The next Section, Section 2, briefly discusses related literature. The following Section 3 describes the data used for the analysis. Section 4 outlines the empirical methodology 
followed, followed by discussion of results in Section 5 . Lastly, Section 6 summarises the paper's findings and concludes with a policy lesson.

\section{Literature Review}

Various studies have analysed different types of factors that could potentially explain the declining trend of FLFP in India. Broadly, these factors can be divided into demand-side and supply-side factors. One of the most initial explanations for the declining FLFP has been the 'feminisation U-curve hypothesis', which was first mentioned by Sinha ${ }^{1}$ and later discussed by many such as Godlin ${ }^{2}$ and Mammen and Paxson ${ }^{3}$. According to the 'feminisation U-curve' hypothesis, as an economy develops, the FLFP of that economy follows a U-shaped curve, ie., it first falls and then rises. This is due to a variety of reasons such as movement of work place farther away from the traditional household farm, stronger incomeeffect of the husband's rising incomes (which in turn reduces the 'need' for a woman to earn).

In the Indian context though, a number of factors have been discussed in the literature, which explains the puzzling trend. A few studies have pointed out that labour force participation of poor women is driven by necessities rather than opportunities. Abraham ${ }^{4}$ shows that under conditions of distress, such as an agrarian crisis, women who are, otherwise, non-working, are forced to enter the labour market to supplement household income. Klasen and Pieters ${ }^{11}$ also support the argument. They find the share of working women in agriculture and manufacturing self-employment and in domestic services increasing, which are mostly poorly paid. This explanation of work force participation being driven by economic poverty has often been called as an 'Income-effect' in various studies, such as Olsen and Mehta ${ }^{5}$, Srivastava and Srivastava ${ }^{6}$ and Himanshu ${ }^{?}$. However, the income-effect has also been cited as working in the opposite way. That is, studies Rangarajan et al. ${ }^{8}$ have also shown that increasing household income reduces the need for women to work and women often withdraw from labour market to attend to domestic duties.

Klasen and Pieters ${ }^{11}$, however, do not find a convincing support to the feminisation U-curve hypothesis in the Indian case. While, other studies have attempted explaining parts of it. Kingdon and Unni ${ }^{9}$ explain the downward sloping part of the U-curve with the help of 'Sankritisation' hypothesis of Chen and Dreze (1992), where they find despite increasing education, women of higher castes participate less in the labour market, due to more rigid social restrictions, specially so up the ladder of caste hierarchy. In line with the same argument, Das and Desai ${ }^{10}$ find cultural factors leading to decline in work force participation of higher-caste women, along with even stronger effects of structural factors that is lack of whitecollar jobs, consistent with rising education levels.

Despite there being spate of evidence on various types of theories explaining the lowering of women's labour force participation, no study has focussed exclusively on withinhousehold factors for the same. This study, thus, aims to contribute to this huge strand of literature by focussing on household level factors - specifically, presence of young children in the household, and hence impact of child-care responsibilities, in explaining the decline of FLFP.

More in line with this study, Sudarshan and Bhattacharya ${ }^{\frac{12}{2}}$, using a primary survey in urban Delhi, find that reproductive work and domestic roles act as significant factors in influencing FLFP They, however, do not empirically quantify this effect by exclusively controlling for the effect of presence of young children.

There are plenty of older studies, however, which indirectly look at the impact of having children on their mother's overall welfare, through the impact of the so-called 'double-burden' of paid and unpaid work (which basically means the household chores and childcare). Bratberg et al. ${ }^{15}$ analyse the effect of 'double-burden', as measured by the increasing number of children, faced by Norwegian women on the increased probability of their sickness. Other studies, such as those by Barnett $\frac{13}{3}$ and Bird ${ }^{14}$ discusses the psychological effects of gendered division of unpaid work and hence, of child-care, on women. MacDonald et al. ${ }^{16}$ find that women in Canada share greater share of unpaid work (such as elder care, household chores and child-care) and hence are more stressed as compared to men. However, most of this huge strand of literature is in the context of advanced countries, and not in the context of developing countries like India. Hence, this study intends to contribute by specifically analysing the role of child-care responsibilities on women's work, in the context of India.

\section{Data}

The data used for studying the discussed research questions is the third round (2005-06) of nationally representative data set - National Family Health Survey. The study's aim, thus, is to undertake a cross-sectional analysis. 
NFHS is a periodically collected multi-topic data set, representative at state and national level. The dataset has information on a variety of household characteristics, with more detailed information on the 'eligible woman' - identified as all women of age 15-49 years in every household. The third round of the survey was conducted in years 2005-06. Since the focus of the study is women's labour force participation, we use women's data and merge it with household dataset to map household characteristics. More than 124,000 eligible women were interviewed in this survey round, of which around 25 percent women report to be 'never married'. Since the aim of study is to analyse the effect of women's children on their work, we use data on only those eligible women who were ever married ${ }^{b}$. Thus, for the full-sample analysis, there are a total of 93,724 eligible women in our analysis.

The data set allows us to analyse patterns of women's employment through the detailed manner in which it captures information on the same. Thus, we use information on women's employment status ie., 1. whether she works at all or not; as well as nature of her employment ie., 2. whether she works at home or away from home; and 3. whether she works for full-year or occasionally/seasonally. This leads to three different dependent variables in our regression analyses.

Similarly, through household roster, we have information on the age-group as well as number of children in each age-group that the woman has. This is the main variable of interest for our analysis. We use different variations of this information and try different models to run the analysis, which is discussed in detail in the next section. Apart from the main variable, we use information on a bunch of other household characteristics, which are discussed in detail in the ensuing sections.

\section{Empirical Methodology}

Using the NFHS-3 dataset, we undertake a cross-sectional analysis of the effect of various factors on women's work, with specific focus on presence of young kids in the household. The factors we consider for our analysis are broadly divided into 'woman-level characteristics' and 'household level characteristics'.

Woman-level characteristics include eligible woman's age and age-squared (to account for non-linearity of relationship), her own education as well as her husband's education - measured in single years, factors related to her bargaining power within the household such as age at marriage and whether she reads newspaper, watches TV or listens to radio; and most importantly, the agedistribution and composition of her children.

Household characteristics, on the other hand, include household demographics such as household size, sex of household head and number of eligible women in the household (an indicator for the family type - nuclear or joint). Household's socio-economic status is taken into account by including variables such as caste and religion of the household, residence type of the household - urban or rural, and household's wealth index, which takes values depending on whether the household belongs to the poorest, poorer, middle, richer or richest wealth quintile.

We also control for state-level fixed effects, by including state dummies, which indicate various policy and institutional level factors affecting employment, in general, such as social and economic infrastructure, political will etc.; and employment of women in particular, such as socio-cultural norms and other societal level factors.

The empirical model can, thus, be described as follows:

$$
\begin{aligned}
\text { FLFP }_{i h s} & =\beta_{0 i h s}+\Sigma_{j=x} \beta_{1 j} X_{i h s}+\Sigma_{j=w} \beta_{2 j} W_{i h s} \\
& +\Sigma_{j=h h} \beta_{3 j} H H_{i h s}+\Sigma_{j=s} \beta_{4 j} S_{s}+\epsilon_{i h s}
\end{aligned}
$$

In Equation (1), the dependent variable, indicates the status/nature of employment of woman ' $i$ ' residing in household ' $h$ ' and state 's'. On the right-hand side, include all the woman-level characteristics which described earlier, are the household level factors and are the state level fixed effects. Lastly, is the error term and includes the effects of all unobservable factors.

The main variable of interest is given by, which indicates the number and age-group of woman's childrenc The basic aim of this variable to identify whether a woman has children of very young age-groups, that is $0-5$, or in some cases even younger, $0-3$, or not. We model this variable in three different ways, described as follows:

Model 1: In model 1, variable $X_{\text {ihs }}$ is defined as a categorical variable which takes value 0 if the eligible woman has no child, 1 if she has 'at least one' child belonging to age-group 0-5, 2 if she has 'at least one' child of age 6-10 and 3 if 'all' her children are of age greater than 10 .

Model 2: In model 2, variable $X_{\text {ihs }}$ is, again, defined a categorical variable, but with much finer categories of age-groups and composition of children. As before, it takes value 0 if the woman has no child. It takes values 1 , 
2, 3, 4, 5 and 6 if 'all' her children belong to the age-groups $0-3,4-7,8-11,12-15,16-19$ and 20 above, respectively. Apart from identifying women who have 'all' their children in specific age-groups, it is important to take into account composition of woman's total children into those belonging to very young age-groups and not-so-young age-groups. Thus, this variable takes value 7 if she has 'all' her children in two age-groups - 0-3 and 4-7, 8 if 'all' children are of age-groups 0-3 and 8-11, 9 for age-groups 0-3 and 12-15, 10 for age-groups 0-3 and 16-19 and 11 for 'all' children of age-groups 0-3 and 20 above. Lastly, the variable takes value 12 if the children belong to any other age-distribution and composition, which are not included in earlier categories.

Model 3: In model 3, variable $X_{\text {ihs }}$ departs from a single categorical variable to multiple continuous variables. It now includes the 'number' of children that the woman has, in the corresponding age-groups discussed in model 2 . ie., $X s$ are, now, the number of children in age-groups 0-3, 4-7, 8-11, 12-15, 16-19 and 20 and above.

Hence, using the specification described in Equation (1), we estimate three models, with three different dependent variables. The results for each dependent variable and each model is described and discussed in the next section.

\section{Results}

\subsection{Effect on Women's Employment Status - Whether She Works or Not}

First, we estimate the effect of aforementioned factors on the probability of a 'woman currently working or not', using a Logit regression. Thus, the dependent variable in Equation (1), is a dummy variable, taking value ' 1 ' is the eligible woman reports to be 'currently working' and ' 0 ' if not.

Table 1, below, shows the results of all three models, for this regression 1, where the dependent variable is a dummy for whether woman chooses to work or not,

As per model 1, we find that compared to a woman who has no child, a woman with at least one child in the younger age-group 0-5 is significantly lesser likely to be currently working. On the other hand, women with at least one child of elderly age-groups, that is ages 6-10 and above 10, are more likely to work. Consistent with the findings of model 1 , model 2 also shows that presence of young children matters for a woman's decision to work, but it matters more if the children belong to very young ages of 0-3. Thus, compared to a woman having no child, a woman with all her children belonging to age-group 0-3 is very less likely to be employed. Similarly, women with all her children in ages 0-3 and 4-7, have a significantly lower probability of being employed. However, compared to the base category of no child, women with all their children of ages above 3 are actually more likely to work. Thus, whereas the presence of very small children affects a woman's working decision, the effect is significant only when 'all children' of the woman belong to the young age-categories. The effect goes away if along with very young children (of ages 0-3), there are elder siblings of ages 8 and above. This suggests that the elder siblings in the household may take care of their younger siblings and hence woman's decision to work is not significantly affected by the presence of children in very young ages. Models 1 and 2 includes an additional control for total number of living children, which has an adverse effect on women's working probabilities ie., as the total number of living children of a woman increases, the probability of her working decreases significantly. Lastly, model 3 also reinforces this result. We find that as the number of children in the very young ages of $0-3$ increases, the probability of a woman to work decreases significantly. However, for children in relatively older age-groups, there are mixed results. As the number of children in ages 4-7 and 8-11 increases, a woman is more likely to be employed, with no effects of increasing number of children in ages 12-15 and 16-19; and perverse effects of increasing children of ages 20 and above.

In terms of woman-level characteristics, we find that the probability of a woman working is significantly increasing in her age. Her own education as well as her husband's education has no significant effect on her working decision. The results, however, suggest that more aware women are more likely to be working, as indicated by the coefficients of a woman's frequency of reading newspapers and listening to radio. As discussed earlier, these variables indicate a woman's empowerment manifested through her awareness and knowledge. Thus, women who report to be reading newspaper and listening to radio 'almost daily', are significantly highly likely to be currently working compared to women who do not engage in reading newspaper or listening to radio at all.

Furthermore, we find that women who report to be watching TV 'almost every day' are very less likely to work. One explanation for this could be the income-effect discussed in literature. A woman who reports to be watching 
TV almost daily are likely to belong to those households which have a TV at home, and the possession of a TV in itself is an indicator of a household's economic well-being. Thus, consistent with findings from literature, we find that in economically well-off households, women are less likely to work. This finding is reinforced by the coefficients of the wealth index. Considering a middle-income household as the base, we find that women in relatively poorer households are more likely to work, with the probabilities being higher in the poorest of the households. Similarly, women in relatively richer households are significantly lesser likely to decide to work, with the probabilities being significantly lower in the richest of the households. This finding not only provides evidence to the two hypotheses of 'Income-effect' and 'Sanskritisation' discussed in the literature, but also re-affirms a commonly cited phenomenon of women's work participation driven by distress, rather than opportunities. All these results are consistent across the three models.

In terms of household's demography, women in femaleheaded households are more likely to work, as in these households, women are likely to have a greater autonomy, compared to male-headed households. While Muslim and Sikh women are much less likely to work, as compared to Hindu women, Christian women are more likely to work.

This study finds evidence of the 'Sanskritisation' hypothesis as well. We find that compared to women belonging to lower caste categories (specifically, Scheduled Castes - SCs), probability of working for women belonging to higher caste is significantly lower. This could be indicative of more rigid social structure above the ladder of caste hierarchy. Moreover, while women belonging to Other Backward Classes (OBCs) are no different from the $\mathrm{SC}$ women, those belonging to Scheduled Tribes (STs) are more likely to work than those belonging to SCs.

Lastly, we find that the probability of participation in the labour maker is significantly higher for women in rural areas, than in urban areas. Again, all findings are consistent across the three models.

\subsection{Effect on Women's Place of Work - Whether She Works at Home or Away from Home}

The study extends the analysis by digging deeper into the kind of jobs women take, given that they are currently working. Thus, whereas the first regression answers the question of whether presence of children matters for a woman's decision to work at all or not; in the second regression, we test the hypothesis of whether presence of children affects the mobility of women to work. That is, given that a woman decides to work, is she more likely to work from home or can she travel or move out farther away from home for work, in the presence of young children in the household? This question is relevant in understanding the flexibility that a woman has in choosing her place of work and hence the choice set of job opportunities to choose from. Therefore, in the absence of an appropriate institutional support, if a woman has children of very young ages, she may be constrained to choose to work from home as an only option of working available to her due to restricted mobility. Hence, she may drop out of the labour market if she does not find work which she can do from home.

We test this hypothesis by estimating Equation (1) using a Logit model, but with a different dependent variable. The dependent variable, is a dummy variable which, now, takes value ' 1 ' is the eligible woman reports to be 'working away from home' and ' 0 ' if she reports to be working 'at home.' Thus, this regression is run on a subsample of only those women who report to be currently working. It is important to note that as per NFHS, the definition of working at home implies - 'within the area of her house or compound'd.

Table 2 shows the results of the second regression, comparing coefficients of the three models, side-by-side; where the dependent variable is a dummy for whether the woman works away from home.

We find some evidence of the presence of young children restricting a woman's mobility with respect to the decision of her work, consistent across the three ways we define our explanatory variable. Thus, compared to a woman with no child, a woman with at least one child belonging to ages 0-5 is significantly lesser likely to work away from home (model 1); with this effect being driven mostly by children of ages $0-3$, as indicated by model 2 , wherein a woman with all her children in ages 0-3 is less likely to be working away from home, relative to women with no child. Model 3 shows that an increasing number of children in ages 0-3 reduces the probability of working away from home. There is no significant difference in the probabilities of working away from home, for women with children of all other age distributions.

In terms of the effect of women's own characteristics, we find that more educated women are significantly more likely to be working away from home, albeit the effect is of smaller magnitude. This result is indicative of the 
Table 1. Woman's Decision to Work at all (Regression 1)

\begin{tabular}{|c|c|c|c|c|c|c|c|}
\hline & & \multicolumn{2}{|c|}{ Model 1} & \multicolumn{2}{|c|}{ Model 2} & \multicolumn{2}{|c|}{ Model 3} \\
\hline \multicolumn{8}{|c|}{ Main variable $-X$} \\
\hline & Base - No child & \multicolumn{2}{|c|}{-} & & & & \\
\hline At le & ast one child of age $0-5$ & $0.76^{* * *}$ & $(0.02)$ & & & & \\
\hline At lea & st one child of age $6-10$ & $1.14^{* * *}$ & $(0.04)$ & & & & \\
\hline & children of age $>10$ & 1.06 & $(0.04)$ & & & & \\
\hline & Base - No child & & & & & & \\
\hline & All children 0-3 & & & $0.67^{* * *}$ & $(0.02)$ & & \\
\hline & All children 4-7 & & & $1.26^{* * *}$ & $(0.06)$ & & \\
\hline & All children 8-11 & & & $1.49^{* * *}$ & $(0.08)$ & & \\
\hline & All children 12-15 & & & $1.33^{* * *}$ & $(0.08)$ & & \\
\hline & All children 16-19 & & & $1.24^{* *}$ & $(0.09)$ & & \\
\hline & All children $>=20$ & & & 1.07 & $(0.06)$ & & \\
\hline $\mathrm{Ch}$ & ldren in $0-3$ and $4-7$ & & & $0.87^{* *}$ & $(0.04)$ & & \\
\hline & iildren $0-3$ and $8-11$ & & & 0.93 & $(0.07)$ & & \\
\hline $\mathrm{Ch}$ & ildren $0-3$ and $12-15$ & & & 0.77 & $(0.14)$ & & \\
\hline $\mathrm{Ch}$ & ildren 0-3 and 16-19 & & & 0.79 & $(0.40)$ & & \\
\hline $\mathrm{Ch}$ & ildren $0-3$ and $>=20$ & & & 0.25 & $(0.19)$ & & \\
\hline & Other categories & & & $1.28^{* * *}$ & $(0.06)$ & & \\
\hline Nun & ber of children in $0-3$ & & & & & $0.71^{* * *}$ & $(0.01)$ \\
\hline Nun & ber of children in $4-7$ & & & & & $1.05^{* * *}$ & $(0.01)$ \\
\hline $\mathrm{Nur}$ & nber of children $8-11$ & & & & & $1.05^{* * *}$ & $(0.01)$ \\
\hline Nun & ber of children $12-15$ & & & & & 1.01 & $(0.01)$ \\
\hline Nun & ber of children 16-19 & & & & & 0.97 & $(0.01)$ \\
\hline Nun & aber of children $>=20$ & & & & & $0.91^{* * *}$ & $(0.01)$ \\
\hline \multicolumn{8}{|c|}{ Woman-level characteristics } \\
\hline & Age & $1.27^{* * *}$ & $(0.01)$ & $1.22^{* * *}$ & $(0.01)$ & $1.22^{* * *}$ & $(0.01)$ \\
\hline & Age-squared & $1.00^{* * *}$ & $(0.00)$ & $1.00^{* * *}$ & $(0.00)$ & $1.00^{* * *}$ & $(0.00)$ \\
\hline Own ec & ucation (in single years) & 1.00 & $(0.00)$ & 1.00 & $(0.00)$ & 1.00 & $(0.00)$ \\
\hline Husband' & education (in single years) & 1.00 & $(0.00)$ & 1.00 & $(0.00)$ & 1.00 & $(0.00)$ \\
\hline Nun & ber of living children & $0.95^{* * *}$ & $(0.01)$ & $0.94^{* * *}$ & $(0.01)$ & & \\
\hline & ge at first marriage & 1.00 & $(0.00)$ & 1.00 & $(0.00)$ & 1.00 & $(0.00)$ \\
\hline \multirow{3}{*}{$\begin{array}{l}\text { Reads } \\
\text { news- } \\
\text { papers }\end{array}$} & less than once a week & $0.87^{* * *}$ & $(0.02)$ & $0.87^{* * *}$ & $(0.02)$ & $0.87^{* * *}$ & $(0.02)$ \\
\hline & at least once a week & $0.91^{* *}$ & $(0.03)$ & $0.91^{* *}$ & $(0.03)$ & $0.91^{* *}$ & $(0.03)$ \\
\hline & almost every day & $1.24^{* * *}$ & $(0.04)$ & $1.23^{* * *}$ & $(0.04)$ & $1.23^{* * *}$ & $(0.04)$ \\
\hline \multirow{3}{*}{$\begin{array}{l}\text { Listens } \\
\text { to radio }\end{array}$} & less than once a week & $1.07^{* *}$ & $(0.02)$ & $1.07^{* *}$ & $(0.02)$ & $1.07^{* *}$ & $(0.02)$ \\
\hline & at least once a week & 1.03 & $(0.03)$ & 1.04 & $(0.03)$ & 1.04 & $(0.03)$ \\
\hline & almost every day & $1.11^{* * *}$ & $(0.03)$ & $1.11^{* * *}$ & $(0.03)$ & $1.11^{* * *}$ & $(0.03)$ \\
\hline
\end{tabular}




\begin{tabular}{|c|c|c|c|c|c|c|c|}
\hline \multirow{3}{*}{$\begin{array}{c}\text { Watches } \\
\text { TV }\end{array}$} & less than once a week & 1.04 & $(0.03)$ & 1.04 & $(0.03)$ & 1.04 & $(0.03)$ \\
\hline & at least once a week & 0.96 & $(0.03)$ & 0.95 & $(0.03)$ & 0.95 & $(0.03)$ \\
\hline & almost every day & $0.80^{* * *}$ & $(0.02)$ & $0.80^{* * *}$ & $(0.02)$ & $0.79^{* * *}$ & $(0.02)$ \\
\hline \multicolumn{8}{|c|}{$\underline{\text { Household-level characteristics }}$} \\
\hline Sex of & ousehold head - female & $1.45^{* * *}$ & $(0.03)$ & $1.46^{* * *}$ & $(0.03)$ & $1.45^{* * *}$ & $(0.03)$ \\
\hline \multicolumn{8}{|c|}{ Religion (base - Hindu) } \\
\hline & Muslim & $0.55^{* * *}$ & $(0.02)$ & $0.55^{* * *}$ & $(0.02)$ & $0.55^{* * *}$ & $(0.02)$ \\
\hline & Christian & $1.34^{* * *}$ & $(0.06)$ & $1.34^{* * *}$ & $(0.06)$ & $1.34^{* * *}$ & $(0.06)$ \\
\hline & Sikh & $0.58^{* * *}$ & $(0.05)$ & $0.58^{* * *}$ & $(0.05)$ & $0.58^{* * *}$ & $(0.05)$ \\
\hline & Other & 0.99 & $(0.05)$ & 0.98 & $(0.05)$ & 0.99 & $(0.05)$ \\
\hline \multicolumn{8}{|c|}{ Caste (base - scheduled castes) } \\
\hline & Scheduled tribe & $1.46^{* * *}$ & $(0.05)$ & $1.46^{* * *}$ & $(0.05)$ & $1.46^{* * *}$ & $(0.05)$ \\
\hline & her backward class & 0.98 & $(0.02)$ & 0.98 & $(0.02)$ & 0.98 & $(0.02)$ \\
\hline & Upward castes & $0.74^{* * *}$ & $(0.02)$ & $0.73^{* * *}$ & $(0.02)$ & $0.73^{* * *}$ & $(0.02)$ \\
\hline & sidence type - rural & $1.27^{* * *}$ & $(0.03)$ & $1.28^{* * *}$ & $(0.03)$ & $1.28^{* * *}$ & $(0.03)$ \\
\hline & Household size & $0.97^{* * *}$ & $(0.00)$ & $0.98^{* * *}$ & $(0.00)$ & $0.97^{* * *}$ & $(0.00)$ \\
\hline Numl & $\begin{array}{l}\text { er of eligible women in } \\
\text { household }\end{array}$ & $1.07^{* * *}$ & $(0.01)$ & $1.06^{* * *}$ & $(0.01)$ & $1.06^{* * *}$ & $(0.01)$ \\
\hline \multicolumn{8}{|c|}{ Std. of living index (base - middle) } \\
\hline & Poorest & $1.40^{* * *}$ & $(0.04)$ & $1.40^{* * *}$ & $(0.04)$ & $1.42^{* * *}$ & $(0.04)$ \\
\hline & Poorer & $1.26^{* * *}$ & $(0.03)$ & $1.26^{* * *}$ & $(0.03)$ & $1.26^{* * *}$ & $(0.03)$ \\
\hline & Richer & $0.67^{* * *}$ & $(0.02)$ & $0.67^{* * *}$ & $(0.02)$ & $0.67^{* * *}$ & $(0.02)$ \\
\hline & Richest & $0.44^{* * *}$ & $(0.01)$ & $0.43^{* * *}$ & $(0.01)$ & $0.44^{* * *}$ & $(0.01)$ \\
\hline & Constant & $0.00^{* * *}$ & $(0.00)$ & $0.00^{* * *}$ & $(0.00)$ & $0.00^{* * *}$ & $(0.00)$ \\
\hline & State fixed-effects & \multicolumn{2}{|c|}{ Yes } & \multicolumn{2}{|c|}{ Yes } & \multicolumn{2}{|c|}{ Yes } \\
\hline & Observations (N) & \multicolumn{2}{|c|}{89475} & \multicolumn{2}{|c|}{89475} & \multicolumn{2}{|c|}{89475} \\
\hline
\end{tabular}

Note: The reported coefficients are exponentiated coefficients and are to be interpreted as 'odds-ratios'. A value less than 1 indicates lesser likelihood and a value greater than 1 indicates higher likelihood.

Standard errors are reported in parentheses.

${ }^{*} p<0.05,{ }^{* *} p<0.01,{ }^{* * *} p<0.001$

nature of jobs that more educated women are likely to get; whereas lesser educated women are more likely to be self-employed and hence, working from home. We also find that as the age at marriage for a woman increases, she is more likely to work away from home, than working at home. The decision of working away from home requires a certain level of decision-making authority and empowerment, which is indicated by an increasing age at which a woman gets married; hence, the result.

Results show that women who read newspaper with low frequency are lesser likely to be working away from home, with no significant advantage to women reading newspapers on daily basis. In terms of exposure to media, we find that women who watch TV and listen to radio with lower frequency (ie., less than once in a week), are more likely to be working away from home. However, a more regular exposure to TV and radio - on a daily basis - reduces the likelihood of women to work away from home. This result might indicate the interplay of 'Income-effect' and 'Sanskritisation' hypotheses in some sense. That is, women with regular exposure to TV and radio are likely to belong to those households which possess a TV and/or radio, and hence are relatively betteroff households in terms of economic well-being. The two 
hypotheses would then mean that even if women from such households decide to work, they are more likely to be engaged in occupations which are 'at home' jobs - such as small household businesses, or skilled professions like tailor, etc.

Once again, the 'Income-effect' hypothesis is reinforced by the finding of effect of household wealth index on women's probability of working away from home. In line with the hypothesis, women belonging to richer and the richest households are much less likely to work away from home, compared to those of middle-income households; and women belonging to poorer and the poorest of the households are much more likely to move/travel away from home for work. The effect gets stronger as the wealth status intensifies, ie., effects are strongest for the poorest and richest households.

Women living in female-headed households have significantly higher probability of working away from home. This result, once again, points to the role of decisionmaking authority of women within the household and relative level of empowerment, as indicated by the headship status. We further find that upper caste women are significantly lesser likely to work away from home, compared to scheduled caste women, hence indicating the role of 'Sanskritisation' hypothesis. Additionally, while Muslim and Sikh women are less likely, Christian women are more likely to work away from home, compared to Hindu women.

Furthermore, women in rural areas are much more likely to work away from home, compared to women residing in urban areas. Thus, not only are rural women more likely to work (regression 1), they are also more likely to work away from home (regression 2).

All these findings are consistent and similar in magnitude across the three models.

\subsection{Effect on Women's Nature of Work - Whether She Works for Full-Year or Not}

Lastly, in addition to affecting a woman's decision of 'where to work', presence of young children may also affect the timeline for which a woman gets employment - ie., whether she gets a job for the full-year or only for some part of the year. Thus, similar to analysis in regression 2 , since this analysis is also conditional on the fact that a woman reports to be working, regression 3 is run on a sub-sample of currently working women. As discussed earlier, understanding this is important to understand the flexibility of choice of work for a woman. Due to child-care responsibilities, a woman may not have the flexibility of working for the full-year, but only for brief periods of time in the year.

Thus, for testing this hypothesis, we run our regression equation using a dichotomous dependent variable (same as in Equation (1), which takes value ' 1 ' if a woman worked for the full-year and ' 0 ' if not. It is important to note that, as per NFHS, if a woman is working even parttime, but that employment is for the full-year, then she is considered to be employed for 'full-year.' Other than full-year, the woman is employed either seasonally - say, only during the sowing season; or occasionally, that is when she responds 'once in a while. Thus, the responses of employed 'occasionally' or 'seasonally' has been converted into the part-year category.

Results for this regression are shown in Table 3 below, for all three models, with the dependent variable as an indicator of whether the woman is employed for the whole year.

Our results show weak evidence of the effect of presence of young kids on women's nature/stability of employment. As per model 1, compared to a woman having no child, while a woman with at least one child in age-group 0-5 is no different, a woman with at least child of older age-group that is $6-10$, is significantly more likely to be employed for full-year. The effect is not significant for a woman with all children of ages greater than 10. In model 2 also, we do not find any significant disadvantage to woman who has all her children belonging to very young ages (0-3), compared to women with no children. However, in model 3 , we find that as a woman's children in the age-group 0-3 increases, her probability of being employed for the whole year decreases significantly. Therefore, while we do find that the presence of young children affects the long-term or short-term nature of women's work, the result is not robust across the three models.

Additionally, we find that higher educated women are more likely to be employed full-time, as they are more likely to land-up in more stable jobs, such as salaried employment (teacher, nurse etc.). As an important indicator of women's awareness, we find that women who report to be reading newspaper on a daily basis are more likely to be employed for full-year. Contradictorily though, we find that women who report to be watching $\mathrm{TV}$ and listening to radio, albeit less frequently, are lesser likely to be employed for full-year. 
Table 2. Woman's Choice of where to Work, Given her Decision to Work (Regression 2)

\begin{tabular}{|c|c|c|c|c|c|c|c|}
\hline & & \multicolumn{2}{|c|}{ Model 1} & \multicolumn{2}{|c|}{ Model 2} & \multicolumn{2}{|c|}{ Model 3} \\
\hline \multicolumn{8}{|c|}{ Main variable $-X$} \\
\hline & Base - No child & \multicolumn{2}{|c|}{-} & & & & \\
\hline At le & st one child of age $0-5$ & $0.89^{*}$ & $(0.05)$ & & & & \\
\hline At le & st one child of age 6-10 & 1.00 & $(0.07)$ & & & & \\
\hline & children of age $>10$ & 1.06 & $(0.08)$ & & & & \\
\hline & Base - No child & & & & & & \\
\hline & All children $0-3$ & & & $0.87^{*}$ & $(0.06)$ & & \\
\hline & All children 4-7 & & & 0.99 & $(0.08)$ & & \\
\hline & All children 8-11 & & & 0.99 & $(0.09)$ & & \\
\hline & All children $12-15$ & & & 1.04 & $(0.11)$ & & \\
\hline & All children 16-19 & & & 1.26 & $(0.15)$ & & \\
\hline & All children $>=20$ & & & 1.12 & $(0.11)$ & & \\
\hline & ldren in $0-3$ and $4-7$ & & & 0.89 & $(0.06)$ & & \\
\hline & ildren $0-3$ and $8-11$ & & & 0.90 & $(0.12)$ & & \\
\hline & ldren $0-3$ and $12-15$ & & & 1.02 & $(0.31)$ & & \\
\hline & ldren 0-3 and 16-19 & & & 1.41 & $(1.18)$ & & \\
\hline & ldren $0-3$ and $>=20$ & & & 1.00 & (.) & & \\
\hline & Other categories & & & 0.99 & $(0.07)$ & & \\
\hline $\mathrm{Nur}$ & ber of children in $0-3$ & & & & & $0.93^{* *}$ & $(0.03)$ \\
\hline $\mathrm{Nul}$ & ber of children in $4-7$ & & & & & 0.98 & $(0.02)$ \\
\hline $\mathrm{Nu}$ & aber of children 8-11 & & & & & 0.98 & $(0.02)$ \\
\hline $\mathrm{Nu}$ & ber of children $12-15$ & & & & & 1.02 & $(0.02)$ \\
\hline $\mathrm{Nu}$ & ber of children 16-19 & & & & & 1.00 & $(0.03)$ \\
\hline $\mathrm{Nu}$ & ber of children $>=20$ & & & & & 1.01 & $(0.02)$ \\
\hline \multicolumn{8}{|c|}{ Woman-level characteristics } \\
\hline & Age & 1.01 & $(0.02)$ & 1.01 & $(0.02)$ & 1.02 & $(0.02)$ \\
\hline & Age-squared & 1.00 & $(0.00)$ & 1.00 & $(0.00)$ & 1.00 & $(0.00)$ \\
\hline Own e & ucation (in single years) & $1.02^{* * *}$ & $(0.01)$ & $1.02^{* * *}$ & $(0.01)$ & $1.02^{* * *}$ & $(0.01)$ \\
\hline Husband & education (in single years) & $1.00^{*}$ & $(0.00)$ & $1.00^{*}$ & $(0.00)$ & $1.00^{*}$ & $(0.00)$ \\
\hline $\mathrm{Nu}$ & ber of living children & 0.99 & $(0.01)$ & 1.00 & $(0.01)$ & & \\
\hline & ge at first marriage & $1.02^{* *}$ & $(0.00)$ & $1.02^{* *}$ & $(0.00)$ & $1.01^{* *}$ & $(0.00)$ \\
\hline \multirow{3}{*}{$\begin{array}{l}\text { Reads } \\
\text { news- } \\
\text { papers }\end{array}$} & less than once a week & $0.67^{* * *}$ & $(0.03)$ & $0.67^{* * *}$ & $(0.03)$ & $0.67^{* * *}$ & $(0.03)$ \\
\hline & at least once a week & $0.73^{* * *}$ & $(0.04)$ & $0.73^{* * *}$ & $(0.04)$ & $0.73^{* * *}$ & $(0.04)$ \\
\hline & almost every day & 1.03 & $(0.07)$ & 1.03 & $(0.07)$ & 1.03 & $(0.07)$ \\
\hline \multirow{3}{*}{$\begin{array}{l}\text { Listens } \\
\text { to radio }\end{array}$} & less than once a week & $1.14^{* *}$ & $(0.05)$ & $1.14^{* *}$ & $(0.05)$ & $1.14^{* *}$ & $(0.05)$ \\
\hline & at least once a week & 1.06 & $(0.05)$ & 1.06 & $(0.05)$ & 1.06 & $(0.05)$ \\
\hline & almost every day & $0.89^{* *}$ & $(0.04)$ & $0.89^{* *}$ & $(0.04)$ & $0.89^{* *}$ & $(0.04)$ \\
\hline
\end{tabular}




\begin{tabular}{|c|c|c|c|c|c|c|c|}
\hline \multirow{3}{*}{$\begin{array}{c}\text { Watches } \\
\text { TV }\end{array}$} & less than once a week & $1.16^{* *}$ & $(0.06)$ & $1.16^{*}$ & $(0.06)$ & $1.16^{* *}$ & $(0.06)$ \\
\hline & at least once a week & 0.93 & $(0.04)$ & 0.93 & $(0.04)$ & 0.93 & $(0.04)$ \\
\hline & almost every day & $0.88^{* *}$ & $(0.04)$ & $0.88^{* *}$ & $(0.04)$ & $0.88^{* *}$ & $(0.04)$ \\
\hline \multicolumn{8}{|c|}{ Household-level characteristics } \\
\hline \multicolumn{2}{|c|}{ Sex of household head - female } & $1.26^{* * *}$ & $(0.05)$ & $1.26^{* * *}$ & $(0.05)$ & $1.27^{* * *}$ & $(0.05)$ \\
\hline \multicolumn{8}{|c|}{ Religion (base - Hindu) } \\
\hline & Muslim & $0.34^{* * *}$ & $(0.02)$ & $0.34^{* * *}$ & $(0.02)$ & $0.34^{* * *}$ & $(0.02)$ \\
\hline & Christian & $1.29^{* * *}$ & $(0.10)$ & $1.29^{* * *}$ & $(0.10)$ & $1.29^{* * *}$ & $(0.10)$ \\
\hline & Sikh & $0.64^{* * *}$ & $(0.08)$ & $0.64^{* * *}$ & $(0.08)$ & $0.64^{* * *}$ & $(0.08)$ \\
\hline & Other & 1.04 & $(0.09)$ & 1.04 & $(0.09)$ & 1.04 & $(0.09)$ \\
\hline \multicolumn{8}{|c|}{ Caste (base - scheduled caste) } \\
\hline & Scheduled tribe & 0.96 & $(0.05)$ & 0.96 & $(0.05)$ & 0.96 & $(0.05)$ \\
\hline & ther backward class & $0.81^{* * *}$ & $(0.03)$ & $0.81^{* * *}$ & $(0.03)$ & $0.81^{* * *}$ & $(0.03)$ \\
\hline & Upward castes & $0.72^{* * *}$ & $(0.03)$ & $0.72^{* * *}$ & $(0.03)$ & $0.72^{* * *}$ & $(0.03)$ \\
\hline & sidence type - rural & $1.33^{* * *}$ & $(0.05)$ & $1.34^{* * *}$ & $(0.05)$ & $1.33^{* * *}$ & $(0.05)$ \\
\hline & Household size & $1.03^{* * *}$ & $(0.01)$ & $1.03^{* * *}$ & $(0.01)$ & $1.03^{* * *}$ & $(0.01)$ \\
\hline Num & $\begin{array}{l}\text { hor of eligible women in } \\
\text { household }\end{array}$ & 1.00 & $(0.02)$ & 1.00 & $(0.02)$ & 0.99 & $(0.02)$ \\
\hline \multicolumn{8}{|c|}{ Std. of living index (base - middle) } \\
\hline & Poorest & $1.80^{* * *}$ & $(0.10)$ & $1.80^{* * *}$ & $(0.10)$ & $1.82^{* * *}$ & $(0.10)$ \\
\hline & Poorest & $1.34^{* * *}$ & $(0.06)$ & $1.34^{* * *}$ & $(0.06)$ & $1.34^{* * *}$ & $(0.06)$ \\
\hline & Richer & $0.58^{* * *}$ & $(0.03)$ & $0.58^{* * *}$ & $(0.03)$ & $0.58^{* * *}$ & $(0.03)$ \\
\hline & Richest & $0.51^{* * *}$ & $(0.03)$ & $0.51^{* * *}$ & $(0.03)$ & $0.51^{* * *}$ & $(0.03)$ \\
\hline & Constant & 1.77 & $(0.54)$ & 1.73 & $(0.55)$ & 1.59 & $(0.51)$ \\
\hline & State fixed-effects & \multicolumn{2}{|c|}{ Yes } & \multicolumn{2}{|c|}{ Yes } & \multicolumn{2}{|c|}{ Yes } \\
\hline & Observations (N) & \multicolumn{2}{|c|}{37529} & \multicolumn{2}{|c|}{37529} & \multicolumn{2}{|c|}{37529} \\
\hline
\end{tabular}

Note: The reported coefficients are exponentiated coefficients and are to be interpreted as 'odds-ratios'. A value less than 1 indicates lesser likelihood and a value greater than 1 indicates higher likelihood.

Standard errors are reported in parentheses.

Remember that this regression is run on a sub-sample of those women who report to be 'currently working'. ${ }^{*} p<0.05,{ }^{* *} p<0.01,{ }^{* * *} p<0.001$

Similarly, consistent with findings of previous regressions, women of female-headed households are more likely to be employed for the full-year; which can be attributed to higher decision-making authority and empowerment of women within such households.

In this specification, we find that Muslim and Sikh women are no different from Hindu women in terms of the stability of their work, but Christian women are more likely to be employed for full-year, compared to Hindu women. Moreover, contrary to findings from previous two regressions, we find no effect of caste on the nature of work that a woman gets.
Importantly though, we find that rural women are very less likely to be employed for the full-year than urban women. This is particularly due to the nature of jobs available in rural areas, which are mostly seasonal in nature.

Lastly, women in the poorest of the households are lesser likely to be employed for the full-year, compared to those of middle-income households; whereas, those belonging to the richer and richest households are much more likely to be employed for the full-year.

As earlier, our findings are all consistent across the three models, unless specified otherwise. 
Table 3. Woman's Work for Full-Year or Not (Regression 3)

\begin{tabular}{|c|c|c|c|c|c|c|c|}
\hline & & \multicolumn{2}{|c|}{ Model 1} & \multicolumn{2}{|c|}{ Model 2} & \multicolumn{2}{|c|}{ Model 3} \\
\hline \multicolumn{8}{|c|}{ Main variable $-X$} \\
\hline & Base - No child & \multicolumn{2}{|c|}{-} & & & & \\
\hline At 1 & ast one child of age $0-5$ & 1.04 & $(0.05)$ & & & & \\
\hline At le & st one child of age 6-10 & $1.16^{*}$ & $(0.07)$ & & & & \\
\hline & l children of age $>10$ & 1.12 & $(0.07)$ & & & & \\
\hline & Base - No child & & & & & & \\
\hline & All children 0-3 & & & 1.03 & $(0.06)$ & & \\
\hline & All children 4-7 & & & $1.24^{* *}$ & $(0.09)$ & & \\
\hline & All children 8-11 & & & 1.08 & $(0.09)$ & & \\
\hline & All children 12-15 & & & $1.26^{*}$ & $(0.12)$ & & \\
\hline & All children 16-19 & & & 1.16 & $(0.12)$ & & \\
\hline & All children $>=20$ & & & 1.09 & $(0.09)$ & & \\
\hline & ildren in $0-3$ and $4-7$ & & & 1.04 & $(0.06)$ & & \\
\hline & tildren $0-3$ and $8-11$ & & & 1.22 & $(0.15)$ & & \\
\hline & ildren $0-3$ and $12-15$ & & & 0.85 & $(0.23)$ & & \\
\hline & ildren 0-3 and 16-19 & & & 0.72 & $(0.58)$ & & \\
\hline & ildren $0-3$ and $>=20$ & & & 0.69 & $(1.00)$ & & \\
\hline & Other categories & & & $1.18^{* *}$ & $(0.08)$ & & \\
\hline $\mathrm{Nu}$ & iber of children in $0-3$ & & & & & $0.94^{* *}$ & $(0.02)$ \\
\hline $\mathrm{Nu}$ & ber of children in 4-7 & & & & & 1.02 & $(0.02)$ \\
\hline & nber of children $8-11$ & & & & & 1.01 & $(0.02)$ \\
\hline $\mathrm{Nu}$ & aber of children $12-15$ & & & & & 1.00 & $(0.02)$ \\
\hline $\mathrm{Nu}$ & aber of children 16-19 & & & & & 0.99 & $(0.02)$ \\
\hline $\mathrm{Nu}$ & nber of children $>=20$ & & & & & 0.98 & $(0.02)$ \\
\hline \multicolumn{8}{|c|}{ Woman-level characteristics } \\
\hline & Age & $1.08^{* * *}$ & $(0.01)$ & $1.07^{* * *}$ & $(0.01)$ & $1.08^{* * *}$ & $(0.01)$ \\
\hline & Age-squared & $1.00^{* * *}$ & $(0.00)$ & $1.00^{* * *}$ & $(0.00)$ & $1.00^{* * *}$ & $(0.00)$ \\
\hline Own & ducation (in single years) & $1.03^{* * *}$ & $(0.00)$ & $1.03^{* * *}$ & $(0.00)$ & $1.03^{* * *}$ & $(0.00)$ \\
\hline Husband & education (in single years) & 1.00 & $(0.00)$ & 1.00 & $(0.00)$ & 1.00 & $(0.00)$ \\
\hline $\mathrm{Nu}$ & aber of living children & 0.98 & $(0.01)$ & 0.98 & $(0.01)$ & & \\
\hline & ge at first marriage & 1.00 & $(0.00)$ & 1.00 & $(0.00)$ & 1.00 & $(0.00)$ \\
\hline \multirow{3}{*}{$\begin{array}{l}\text { Reads } \\
\text { news- } \\
\text { papers }\end{array}$} & less than once a week & 1.02 & $(0.05)$ & 1.02 & $(0.05)$ & 1.02 & $(0.05)$ \\
\hline & at least once a week & 0.97 & $(0.06)$ & 0.98 & $(0.06)$ & 0.97 & $(0.06)$ \\
\hline & almost every day & $1.58^{* * *}$ & $(0.11)$ & $1.58^{* * *}$ & $(0.11)$ & $1.57^{* * *}$ & $(0.11)$ \\
\hline \multirow{3}{*}{$\begin{array}{l}\text { Listens } \\
\text { to radio }\end{array}$} & less than once a week & $0.90^{* *}$ & $(0.03)$ & $0.89^{* *}$ & $(0.03)$ & $0.89^{* *}$ & $(0.03)$ \\
\hline & at least once a week & $0.88^{* * *}$ & $(0.04)$ & $0.88^{* * *}$ & $(0.04)$ & $0.88^{* *}$ & $(0.04)$ \\
\hline & almost every day & 0.96 & $(0.04)$ & 0.96 & $(0.04)$ & 0.96 & $(0.04)$ \\
\hline \multirow{3}{*}{$\begin{array}{c}\text { Watches } \\
\text { TV }\end{array}$} & less than once a week & $0.88^{* *}$ & $(0.03)$ & $0.88^{* *}$ & $(0.03)$ & $0.88^{* *}$ & $(0.03)$ \\
\hline & at least once a week & $0.84^{* * *}$ & $(0.03)$ & $0.84^{* * *}$ & $(0.03)$ & $0.84^{* * *}$ & $(0.03)$ \\
\hline & almost every day & 0.97 & $(0.04)$ & 0.97 & $(0.04)$ & 0.98 & $(0.04)$ \\
\hline
\end{tabular}




\begin{tabular}{|c|c|c|c|c|c|c|}
\hline \multicolumn{7}{|l|}{ Household-level characteristics } \\
\hline Sex of household head - female & $1.17^{* * *}$ & $(0.04)$ & $1.17^{* *+*}$ & $(0.04)$ & $1.17^{* *+*}$ & $(0.04)$ \\
\hline \multicolumn{7}{|l|}{ Religion (base - Hindu) } \\
\hline Muslim & 0.93 & $(0.05)$ & 0.93 & $(0.05)$ & 0.93 & $(0.05)$ \\
\hline Christian & $1.15^{*}$ & $(0.07)$ & $1.15^{*}$ & $(0.07)$ & $1.15^{*}$ & $(0.07)$ \\
\hline Sikh & 0.94 & $(0.13)$ & 0.94 & $(0.13)$ & 0.94 & $(0.13)$ \\
\hline Other & 0.90 & $(0.07)$ & 0.90 & $(0.07)$ & 0.90 & $(0.07)$ \\
\hline \multicolumn{7}{|l|}{ Caste (base - scheduled caste) } \\
\hline Scheduled tribe & 1.01 & $(0.04)$ & 1.01 & $(0.04)$ & 1.01 & $(0.04)$ \\
\hline Other backward class & 0.97 & $(0.03)$ & 0.97 & $(0.03)$ & 0.97 & $(0.03)$ \\
\hline Upward castes & 0.94 & $(0.04)$ & 0.93 & $(0.04)$ & 0.94 & $(0.04)$ \\
\hline Residence type - rural & $0.48^{* * *}$ & $(0.02)$ & $0.48^{* * *+}$ & $(0.02)$ & $0.48^{*+*+}$ & $(0.02)$ \\
\hline Household size & $0.99^{*}$ & $(0.01)$ & $0.99^{*}$ & $(0.01)$ & $0.99^{*}$ & $(0.01)$ \\
\hline $\begin{array}{l}\text { Number of eligible women in } \\
\text { household }\end{array}$ & 1.03 & $(0.02)$ & 1.02 & $(0.02)$ & 1.02 & $(0.02)$ \\
\hline \multicolumn{7}{|l|}{ Std. of living index (base - middle) } \\
\hline Poorest & $0.88^{* *}$ & $(0.03)$ & $0.88^{* *}$ & $(0.03)$ & $0.88^{* *}$ & $(0.03)$ \\
\hline Poorer & 0.97 & $(0.03)$ & 0.97 & $(0.03)$ & 0.97 & $(0.03)$ \\
\hline Richer & $1.15^{* * *}$ & $(0.04)$ & $1.15^{* * *}$ & $(0.04)$ & $1.16^{* *+*}$ & $(0.04)$ \\
\hline Richest & $1.70^{* * *}$ & $(0.10)$ & $1.69^{* * *}$ & $(0.10)$ & $1.71^{* * *}$ & $(0.10)$ \\
\hline Constant & $2.06^{* *}$ & $(0.56)$ & $2.34^{* *}$ & $(0.65)$ & $2.15^{* *}$ & $(0.60)$ \\
\hline State fixed-effects & \multicolumn{2}{|c|}{ Yes } & \multicolumn{2}{|c|}{ Yes } & \multicolumn{2}{|c|}{ Yes } \\
\hline Observations (N) & \multicolumn{2}{|c|}{37540} & \multicolumn{2}{|c|}{37540} & \multicolumn{2}{|c|}{37540} \\
\hline
\end{tabular}

Note: The reported coefficients are exponentiated coefficients and are to be interpreted as 'odds-ratios'. A value less than 1 indicates lesser likelihood and a value greater than 1 indicates higher likelihood.

Standard errors are reported in parentheses.

Remember that this regression is run on a sub-sample of those women who report to be 'currently working. ${ }^{*} p<0.05,{ }^{* *} p<0.01,{ }^{* * *} p<0.001$

\section{Conclusion}

The main aim of this study is to understand the employment decision of women in India and the role of various own and household level factors that could affect the decision. The study lays special emphasis on the impact of 'childcare responsibilities', which are considered to be sole onus of women, on their work-decisions - ie., whether to work at all or not. This has not been explored well in literature. The study extends the analysis by estimating the impact of 'child-care responsibilities' and other factors, on the place of work and nature of work that women choose. We define the main variable of interest - presence of young children, in three ways, which have been termed as models 1,2 and 3. In models 1 and 2, the variable is defined as a categorical variable indicating presence of children in specific agegroups with coarser and finer intervals, respectively. Model
3 relaxes this and is a continuous variable taking values of the exact number of children in corresponding age-groups.

The three regression analyses with three dependent variables, each run on three models described above give us detailed insights on women's employment in India. We find some support to the existing hypotheses cited in literature, to explain the declining trend of FLFP, or simply the low levels of it.

Firstly, we find strong evidence for role of burden of 'child-care responsibilities' in affecting women's work decisions. Our findings are consistent and comparable across the three models used to define 'presence of young children in the household'. We find that compared to women with children of ages $0-5$, women with no child or with children of older age-groups have significantly higher chances of working (model 1). This effect is driven by presence of or increasing number of children of very young 
age-groups, that is ages 0-3 (models 2 and 3 ). We also find that women with children of ages 0-5 (model 1 ) and more specifically of ages 0-3 (models 2 and 3) are more likely to choose occupations which they can do at home. Hence, there is evidence of the effect of child-care responsibilities on restricting women's work mobility. Lastly, our results show weak evidence for impact of younger children on the duration for which women stay employed. While models 1 and 2 show no significant effects of presence of young children on women's work duration, model 3 shows that as children of ages 0-3 increases, women are significantly lesser likely to be employed for the full-year.

We find support to the 'Income-effect' hypothesis as a possible explanation for low participation rates of women in the labour market. Our results show that women in households with relatively better economic status - as indicated by higher wealth index, possession of TV and radio - have significantly lower probability of participating in the work force, compared to relatively poorer households. This finding also re-affirms the notion that work participation of women is driven by poverty and distress and not really by opportunities. There is also evidence of role of strong cultural norms, as echoed in the 'Sanskritisation' hypothesis. We find that women belonging to higher castes are lesser likely to work, compared to women belonging to lower caste categories, as cultural norms and social restrictions are more rigid in the upper caste groups. All these factors not only affect the decision of women to participate in the labour market but also affect the way they choose their work. Therefore, we find that women belonging to richer households and higher caste groups are also significantly lesser likely to work 'away from home. However, women belonging to lower castes and lower income groups also have lower stability in their work, as they have lower probability of being employed for the full-year.

Expectedly, highly educated, more aware and more empowered women are not only more likely to work, they are also more likely to work away from home and be employed for full-year; as suggested by significant effects of women's own education, higher age at marriage, the household head being a female and women's frequency of reading newspapers.

We also find that not only are women in rural areas more likely to work, they are more likely to work away from home, but lesser likely to be employed for the fullyear. This could be due to the nature of rural employment being predominantly seasonal/occasional.
In the light of these results, our study concludes that rigidity in the social and cultural norms, which are patriarchal in nature, act as an inherent constraint to women's labour force participation. These norms take years to change and any policy intervention directed towards this may not help in addressing the issue of low FLFP in the immediate time period. However, it is important to note that one of the implications of the same strong patriarchal norms has been in defining the role of 'child-care' as that belonging to, primarily, women. It is in this context that the policy-makers can intervene and significantly improve the possibility of women's participation in labour market. One such policy intervention can be the provision of day-care facilities to children of young ages, at an institutional level. This can help remove one of the bigger constraints to women's participation in work force, as well as, also help in the early childhood development (in terms of early education and nutrition) of children as a whole.

\section{References}

1. Sinha JN. Dynamics of female participation in economic activity in a developing economy. Proceedings of the World Population Conference; Belgrade, Vol. 4, Migration, Urbanization, Economic Development, New York: United Nations. 1965.

2. Goldin C. The U-shaped female labor force function in economic development and economic history, in TP Schultz (ed.). Investment in Women's Human Capital and Economic Development, University of Chicago Press, Chicago; 1995. p. 61-90. https://doi.org/10.3386/w4707

3. Mammen K, Paxson C. Women's work and economic development. J. Econ. Perspect. American Economic Association. 2000; 14(4):141-64. https://doi.org/10.1257/ jep.14.4.141

4. Abraham,V. Employment growth in rural India: Distressdriven?' Economic and Political Weekly; 2009. p. 97-104.

5. Olsen W, Mehta S. A pluralist account of labour participation in India. Working Paper, Global Poverty Research Group, Manchester: University of Manchester; 2006.

6. Srivastava N, Srivastava R. Women, work, and employment outcomes in Rural India. Economic and Political Weekly. 2010; 45(28):49-63.

7. Himanshu. Employment trends in India: A re-examination. Economic and Political Weekly. 2011; 46(37):43-59.

8. Rangarajan C, Kaul PI, Seema. Where is the missing labour force? Economic and Political Weekly. 2011; 46(39):68-72. 
9. Kingdon G, Unni J. Education and women's labor market outcomes in India. Education Economics. 2001; 9(2):17395. https://doi.org/10.1080/09645290110056994

10. Das MB, Desai S. Why are educated women less likely to be employed in India? Testing Competing Hypotheses. Social Protection Discussion Paper Series, No. 313. Washington, D.C: World Bank; 2003

11. Klasen S, Pieters J. Push or pull? Drivers of female labor force participation during India's economic boom. 2012.

12. Sudarshan RM, Bhattacharya S. Through the magnifying glass: Women's work and labour force participation in urban Delhi. Economic and Political Weekly; 2009. p. 59-66.

13. Barnett RC. Multiple roles, gender, and psychological distress. Free Press. 1993.

14. Bird CE. Gender, household labor, and psychological distress: The impact of the amount and division of housework. J. Health Soc. Behav. 1999; 40(1):32-45. https://doi.org/10.2307/2676377

15. Bratberg E, Dahl SA, Risa AE. The double burden: Do combinations of career and family obligations increase sickness absence among women? European Sociological Review. 2002; 18(2):233-49. https://doi.org/10.1093/ esr/18.2.233
16. MacDonald M, Phipps S, Lethbridge L. Taking its toll: The influence of paid and unpaid work on women's well-being. Feminist Economics. 2005; 11(1):63-94. https://doi.org/10.1080/1354570042000332597

\section{Notes}

${ }^{a}$ This study defines the age-group of very young children as $0-5$, because typically, this is the age-group of children who necessarily stay at home to be taken care of. At age 6, children, typically, start going to schools. While a number of times, even children of age 6 stay at home, to avoid any confusion, this study intentionally sticks to the age-group 0-5.

${ }^{b}$ An ever-married woman is one who was has ever been married at least once, in her lifetime. This includes - currently married, currently divorced or separated and currently widowed women. Thus, this category leaves out the 'never-married' women.

'We define 'children' as the sons and daughters of a woman, regardless their ages. Thus, even if a woman has a son or daughter of age 18 and above, $s($ he) is identified and termed as the eligible woman's 'child/children'.

${ }^{\mathrm{d}} \mathrm{A}$ woman may work on family fields that are far from the compound; in this case, the response is coded as working 'away from home. If she works on a plot of land just outside the house, response is coded 'working at home'. 